\title{
Combined Traumatic Facial Nerve Repair and Maxillofacial Fractures: Long Term Follow-Up
}

\author{
MOHAMED A.A. SALEH, M.D., M.R.C.S. (Eng.)*; AMR A. GHANEM, M.D.** and \\ GHADA M. ABOU-SHANAB, M.D.***
}

The Department of Plastic, Reconstruction, Maxillofacial Surgeries \& Burn Management, Faculty of Medicine*, Ain Shams University, Oral \& Maxillofacial Surgery Department, Faculty of Dentistry** and Physical Medicine, Rheumatology \& Rehabilitation Department, Faculty of Medicine***, Ain Shams University, Cairo, Egypt

\begin{abstract}
Maxillofacial fractures management is considered a great challenge to facial plastic and reconstructive surgeons. They inquire adequate and systematic patient assessment to exclude involvement of facial neurovascular structures and the airway injuries. Types of fixation differ whether rigid or semi rigid fixation is used according to the degree of comminusion, site and shape of the fracture. The etiology of facial nerve palsy include: Idiopathic, post traumatic, neoplastic, etc... The traumatic injuries are the second most common, caused by personnel assaults, accidental at work or due to road traffic accidents.
\end{abstract}

Searching in the English written literature it is not mentioned the outcome of primary traumatic facial nerve repair combined with complex maxillofacial injuries. The aim of the study is to investigate the long term functional outcome of traumatic facial nerve and maxillofacial fractures reconstruction.

The study reviewed 16 patients with nerve injury and varies types of maxillofacial fractures, at El Demerdash Ain Shams University Hospital between June 2015 and October 2019. Only patients diagnosed with facial nerve main trunk or its branches after examination were included in the study. Only patients with followed-up data for at least 18 months were included. All patients was examined in the post-operative period and assessment was done using the House-Brackmann classification 11 and CT facial bone Patients demographic, history, physical and clinical examination, clinical photographs and surgical procedures (number and type) and complications were collected.

This study revealed that the long term follow-up for patients with repaired facial nerve and varies maxillofacial fractures had promising esthetic and functional with a mean the post-operative objective House-Brackmann score analysis was $2.56( \pm 0.51)$. Further multi centric study is suggested to investigate the relation between the type of trauma, results and different nerves involved and this could be achieved by increasing the number of patients to be included in the future study.

Key Words: Maxillofacial fractures, Facial nerve injury Facial rejuvenation - Complex facial injuries Micro neural repair.

\section{INTRODUCTION}

The anatomical prominence of the face render it vulnerable to injuries. Zygomatic maxillary complex "ZMC" fractures is the second most common after nasal fractures. Its main role is protection of important structures i.e. the eye, and form an integral part of the orbit, maxilla, temporal bone, body and arch of zygoma. Fractures are mainly due to trauma as in road traffic accidents, assaults, fall from a height, sports and work injuries [1].

Maxillofacial fractures management is considered a great challenge to facial plastic and reconstructive surgeons. They inquire adequate and systematic patient assessment to exclude involvement of facial neurovascular structures and the airway injuries. ZMC fractures are treated by open reduction and internal fixation and buttressing fractured sites to stable skeletal platform [2].

Types of fixation differ whether rigid or semi rigid fixation is used according to the degree of comminusion, site and shape of the fracture. Computed tomographic (CT) imaging with multi planar reformation is an integral part of midface fractures investigation [3].

Facial nerve palsy incidence ranges 20 to 30 cases/100,000/annually [4]. The etiology include: Idiopathic, post traumatic, neoplastic etc.... The traumatic injuries are the second most common, caused by personnel assaults, accidental at work or due to road traffic accidents. Road traffic accidents are the leading cause of fractures to the temporal bone and are associated with a $31 \%$ incidence of injury to the facial nerve [5].

Treatment strategies are based on the anatomical integrity of the facial nerve. An injured, however 
intact facial nerve represent a challenging condition, as the prognosis of recovery is difficult to predict. On the other hand, a severed nerve results in severe devastating sequel which might lead to: Exposure keratosis up to blindness, facial asymmetry and disfigurement, impaired nasal airflow, oral sphincteric incompetence and synkinesis [6].

Complete nerve transection of the main trunk or one or more branches of the facial nerve is an indications for immediate or early primary end to end repair [7]. Gun-shot injuries tends is of the worst conditions. Such violence are presenting more commonly nowadays specifically in the USA, because of rising incidence of violence and suicidal attempts. Microsurgical techniques are indicated for injuries posterior to the line drawn from the lateral canthus and repair of distal branches anterior to this line is unnecessary due to the considerable peripheral anastomoses [8]. Standardized clinical examination and assessment of utmost importance that includes analysis of voluntary movements. Most commonly used the House-Brackmann classification however many other classifications are available [9].

If primary repair did not achieve its goals, facial reanimation with secondary procedures such as hypoglossal and masseteric nerve crossovers, dynamic muscle transfer, or static slings, could be used. The goals are to restore the function i.e.: Protect the eye and form to achieve static and dynamic facial symmetry weather voluntary or involuntary facial expression [10].

To our knowledge and searching in the English written literature it is not mentioned the combining outcome of primary facial nerve repair and complex maxillofacial injuries. The aim of the study is to investigate the long term functional and aesthetic outcome of traumatic facial nerve and maxillofacial fractures reconstruction.

\section{PATIENTS AND METHODS}

The study reviewed 16 patients with nerve injury and varies types of maxillofacial fractures, at El Demerdash Ain Shams University Hospital between June 2015 and October 2019. Only patients diagnosed with traumatic facial nerve main trunk or its branches after examination were included in the study. Only patients with followed up data for at least 18 months were included. Patients which required primary nerve graft were excluded from the study. All patients was examined in the postoperative period and assessment was done using the House-Brackmann classification 11 and CT facial bone "coronal, axial, sagittal and 3 dimension views and panorama of the mandible if needed. Patients demographic, history, physical and clinical examination, clinical photographs and surgical procedures (number and type) and complications were collected. All patients or their parents signed an informed consent to be included in the study. Patients demographics is shown in Table (2).

\section{Planning for surgical intervention:}

All patient were operated within 24 hours to 48 hours of trauma. The etiology of trauma was due to road traffic accidents, high velocity impact, fall from height and assaults. After primary survey was done by the emergency department and the patient general condition improved, examination of facial nerve is carried including all regions of the face at rest and animation. Patients were asked to smile to show their teeth, frown and raise their eyebrows and close their eyes. The surgical plane were individualized according to each patient type of trauma. Indication for surgical intervention was based on priority of correction of functional deficit due to the facial nerve affection, repair other import structure injuries i.e. Parotid duct, parotid gland, lower or upper eye lid injuries and insure proper skeletal reduction and stability.

The patient age, functional deficit, fracture site, number, type, preoperative occlusion all are factors which is considered. Patients or their parents were counseled and clearly discussed the nature of the trauma, limitations of surgical outcomes, and the possible secondary procedures for facial rejuvenation to be carried afterward. Involvement of other specialties when needed is of utmost importance e.g.: Ophthalmological, ear nose and throat, and orthodontists according to each patient clinical condition.

Preoperative photography facial nerve examination and surgical incisions:

Incisions chosen based on the: Clinical examination, site, size of the fracture and present lacerations Preoperative and postoperative standardized facial photographs static and during facial animation (frontal, oblique, and lateral views) obtained at least at 6,12 and 18 months. Using the HouseBrackmann (HB) classification Standardized clinical examination is carried to analyze the voluntary movements and document it as follows:

(Grade I - Normal): Normal facial function in all areas. (Grade II - Slight Dysfunction), Gross: slight weakness noticeable on close inspection; may have very slight synkinesis, at rest: Normal symmetry and tone, Motion: Forehead - moderate to good function; eye - complete closure with minimum effort; mouth - slight asymmetry. (Grade 
III - Moderate Dysfunction), gross: obvious but not disfiguring difference between two sides; noticeable but not severe synkinesis, contracture, and/or hemi-facial spasm, at rest: Normal symmetry and tone, Motion: Forehead - slight to moderate movement; eye - complete closure with effort; mouth - slightly weak with maximum effort. (Grade IV - Moderate Severe Dysfunction), Gross: obvious weakness and/or disfiguring asymmetry, At rest: Normal symmetry and tone, Motion: Forehead none; eye - incomplete closure; mouth - asymmetric with maximum effort. (Grade V - Severe Dysfunction), Gross: Only barely perceptible motion, At rest: asymmetry, Motion: Forehead - none; eye incomplete closure; mouth slight movement. (Grade VI - Total Paralysis), No movement Table (1).

Table (1): Showing the House-Brackmann scale.

\begin{tabular}{|c|c|c|c|}
\hline Grade & Description & At rest & In movement \\
\hline I & Normal function in all areas & & \\
\hline II & Mild dysfunction & $\begin{array}{l}\text { Normal symmetry and tone } \\
\text { Gross: Slight weakness noticeable on close } \\
\text { inspection, may have very slight synkinesis }\end{array}$ & $\begin{array}{l}\text { Forehead: Moderate to good function } \\
\text { Eye: Complete closure with minimum } \\
\text { effort } \\
\text { Mouth: Slight asymmetry }\end{array}$ \\
\hline III & Moderate dysfunction & $\begin{array}{l}\text { Normal symmetry and tone } \\
\text { Gross: Obvious but not disfiguring difference } \\
\text { between two sides. noticeable but not severe } \\
\text { synkinesis, contracture, and/or hemifacial } \\
\text { spasm }\end{array}$ & $\begin{array}{l}\text { Forehead: Slight to moderate } \\
\text { movement } \\
\text { Eye: Complete closure with effort } \\
\text { Mouth: Slight weakness with maximum } \\
\text { effort }\end{array}$ \\
\hline IV & Moderately severe dysfunction & $\begin{array}{l}\text { Normal symmetry and tone } \\
\text { Gross: Obvious weakness and/or disfiguring } \\
\text { asymmetry At rest }\end{array}$ & $\begin{array}{l}\text { Front: None } \\
\text { Eye: Incomplete closure } \\
\text { Mouth: Asymmetric with maximum } \\
\text { effort }\end{array}$ \\
\hline V & Severe dysfunction & $\begin{array}{l}\text { Asymmetry } \\
\text { Gross: Only barely perceptible motion At rest }\end{array}$ & $\begin{array}{l}\text { Front: None } \\
\text { Eye: Incomplete closure } \\
\text { Mouth: Slight movement }\end{array}$ \\
\hline VI & Total paralysis & Asymmetry & No movement \\
\hline
\end{tabular}

\section{Surgical details:}

All surgeries were performed under general anesthesia. Broad spectrum antibiotic was administered and. Adequate wash with saline and betadine scrub and removal of foreign bodies i.e. gravel was done prior to sterilization. The surgical microscope was used in all cases. Nerve stimulator was of utmost importance to identifying the nerve injury unless they were obvious during dissection and the bipolar coagulation were used for hemostasis.

The surgical technique used were tailored to each patient clinical condition:

1- Different surgical incisions adopted: Subcilliary, intraoral, preauricular, and current lacerations were used.

2- Excision of the devitalized tissue and removal of foreign bodies if present.

3- Identifying and Preserving important structures i.e.: Levator palpebrae superioris muscle, medial and lateral canthi, facial nerve and its branches, parotid duct, parotid and submandibular gland.
4- Boney skeleton stabilization i.e. open reduction internal fixation using varies types of plate and screws or titanium mesh according to the type and site of fractures, upper and lower arch bar and maxillary mandibular fixation with stainless steel wires as in alveolar fractures or using the elastics as in condylar and high sub condylar fractures.

5- Soft tissue reconstruction using local flaps if needed and repair of injured important structures. Identifying the parotid duct orifice and injection on methylene blue dye was done in all cases to exclude parotid duct and parotid gland injuries. Parotid duct injuries were stinted using an epidural catheter and $6 / 0$ and $7 / 0$ proline stitches was used for its repair. Using the surgical microscope facial nerve injury or its branches were identified followed by minimal debridement if needed and epineurial repair was done using $8 / 0$ and $9 / 0$ ethilon sutures.

6- Identifying injured tissue layers and the repair was done from deep to superficial. Repair of 
any injured mucosal lining, Submuscular aponeurotic system, varies muscle injuries and parotid fascia was done using $3 / 0$ and $4 / 0$ vicryle either in interrupted or continues type.

7- Application of suction drains or rubber drains if needed, followed by skin closure using $5 / 0$ and $6 / 0$ proline stitches.

\section{Post-operative care:}

Light compression dressing were applied to all patients. Patients laid down in semi sitting position. Cold fomentation for the first 48 hours followed by hot fomentation up to two weeks. Intravenous antibiotics administered till the drain is removed, shifting to oral route for one week. Drains removed when it's minimal amount (less than 30cc). Dressing is done at the $5^{\text {th }}$ to $7^{\text {th }}$ postoperative day. In patients with parotid duct injuries, betadine mouth wash is used to improve the oral hygiene, the epidural stent is left for 4 weeks and patient were instructed to avoid acidic fluids or sour meals. Nonabsorbable stitches were removed from post-operative days 7 to 10 . All patients instructed to follow-up in the outpatient clinic at one, three, six, twelve and eighteen months afterward. Patients was informed about possible progress, and possible outcome which might need 2ry procedures for facial rejuvenation.

\section{Post-operative facial nerve rehabilitation:}

All patients were assessed for muscle state and grade documenting clinical deficits carefully, the patients are taught about facial muscles and how it works which in term gives a better outcome in recovery. Eye care, mouth care and personal hygiene are advised carefully.

Also, all patients start effurage massage to the facial muscles, helping increase blood flow to the skin and the underlying muscles and maintaining the muscle tone.

The patients start exercising the facial muscles 3 days postoperative in front of a mirror every day, first trying to move the muscles as if trying to get an activity and then assist the residual range of motion by their hands until they get full motion and range recovered within the rehabilitation period.

According the strength duration curve preformed on all patients, they started interrupted galvanic stimulation program to the affected facial muscles to maintain muscle tone and enhance nerve recovery. At 3, 6, 9 and 18 months, patients are reassessed for their clinical deficits.

\section{Clinical assessment:}

Patients were examined in a regular follow-up intervals as regard: The adequacy of skeletal reduction and fixation by patient's complaints which was correlated to the postoperative CT scan views. HB classification system was used and patient examination was done as regard presence of gross asymmetry and synkinesis, during forehead, eye and mouth action Table (1). Complications rate were record i.e. hematoma, seroma, wound infection, hypertrophic scar, parotid swelling, and 2ry intervention Table (5).

\section{RESULTS}

Patients included in the study age ranged from 8 till 51 years, with mean age $26.37( \pm 12.98)$ years. $75 \%$ Male and $25 \%$ female patients were presented with different types of trauma, see Diagram (1). 3 patients were diabetics (18.75\%), 3 were hypertensive $(18.75 \%)$ and 6 patients were smokers with $37.5 \%$ of all patients Table (2).

Table (2): Patient's demographics.

\begin{tabular}{|c|c|c|c|c|c|c|c|}
\hline \# & Sex & Age & Mode of trauma & Smoking & Diabetes & Hypertension & Hospital stay \\
\hline 1 & 18 & M & Assault & $\mathrm{Y}$ & $\mathrm{N}$ & $\mathrm{N}$ & 3 \\
\hline 2 & 24 & $\mathrm{~F}$ & High velocity impact & $\mathrm{N}$ & $\mathrm{N}$ & $\mathrm{N}$ & 5 \\
\hline 3 & 17 & M & Assault & $\mathrm{Y}$ & $\mathrm{N}$ & $\mathrm{N}$ & 4 \\
\hline 4 & 10 & $\mathrm{~F}$ & FFH & $\mathrm{N}$ & $\mathrm{N}$ & $\mathrm{N}$ & 3 \\
\hline 5 & 43 & M & RTA & $\mathrm{Y}$ & $\mathrm{N}$ & $\mathrm{Y}$ & 4 \\
\hline 6 & 35 & M & High velocity impact & $\mathrm{N}$ & $\mathrm{N}$ & $\mathrm{N}$ & 4 \\
\hline 7 & 39 & M & Assault & $\mathrm{N}$ & $\mathrm{Y}$ & $\mathrm{N}$ & 4 \\
\hline 8 & 22 & $\mathrm{~F}$ & High velocity impact & $\mathrm{N}$ & $\mathrm{N}$ & $\mathrm{N}$ & 5 \\
\hline 9 & 42 & M & Assault & $\mathrm{Y}$ & $\mathrm{Y}$ & $\mathrm{Y}$ & 5 \\
\hline 10 & 8 & M & $\mathrm{FFH}$ & $\mathrm{N}$ & $\mathrm{N}$ & $\mathrm{N}$ & 4 \\
\hline 11 & 16 & M & Assault & $\mathrm{N}$ & $\mathrm{N}$ & $\mathrm{N}$ & 3 \\
\hline 12 & 18 & M & High velocity impact & $\mathrm{Y}$ & $\mathrm{N}$ & $\mathrm{N}$ & 4 \\
\hline 13 & 27 & $\mathrm{~F}$ & Assault & $\mathrm{N}$ & $\mathrm{N}$ & $\mathrm{N}$ & 3 \\
\hline 14 & 51 & M & RTA & $\mathrm{N}$ & $\mathrm{Y}$ & $\mathrm{Y}$ & 3 \\
\hline 15 & 36 & M & High velocity impact & $\mathrm{Y}$ & $\mathrm{N}$ & $\mathrm{N}$ & 5 \\
\hline 16 & 16 & M & Assault & $\mathrm{N}$ & $\mathrm{N}$ & $\mathrm{N}$ & 3 \\
\hline
\end{tabular}

FFH: Fall from height. RTA: Road traffic accident. 
Mode of trauma

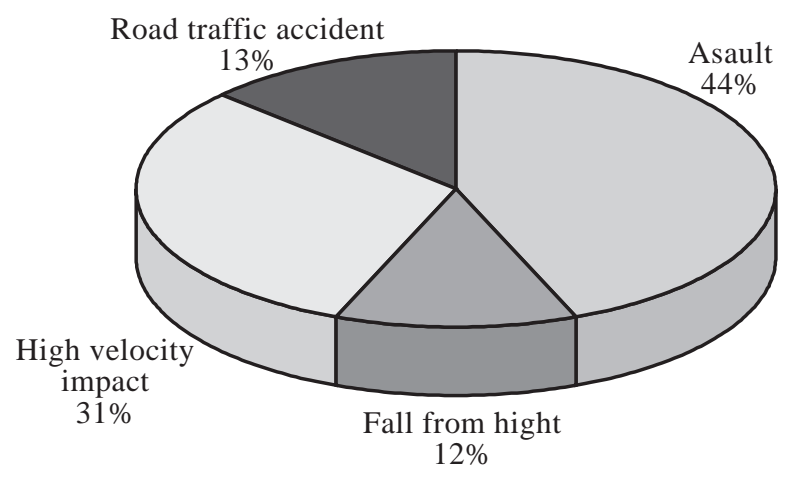

Diagram (1): Percentages of patients according to mode of trauma.
The mean follow-up time was 24 month $( \pm 4)$ months with maximum time in patients having main trunk facial nerve injury 28 months and minimum in patients having buccal branch of facial nerve injury 18 months. The mean hospital stays $3.875( \pm 0.81)$ days. The longest hospital stays 5 days in patients having main trunk facial nerve and fracture zygoma and shortest 3 days in patients having buccal branch of facial nerve and condylar injury. 2 patients needed a $2^{\text {nd }}$ surgical procedures for 2 ry sutures and scar revision.

Distribution of Maxillo-facial fractures, facial nerve, other structures injury and their management are shown in Table (3).

Table (3): Distribution of injuries and their management.

\begin{tabular}{|c|c|c|c|c|c|c|c|c|c|c|c|}
\hline \multicolumn{3}{|c|}{ Facial branch injured } & \multicolumn{3}{|c|}{ Parotid duct injury } & \multicolumn{3}{|c|}{ Site of facial fracture } & \multicolumn{3}{|c|}{ Management of facial fractures } \\
\hline Buccal & 6 & $37.50 \%$ & Injured & 8 & $50 \%$ & Condylar & 2 & $12.50 \%$ & Arch bar & 4 & $25 \%$ \\
\hline Temporal & 2 & $12.50 \%$ & Not injured & 8 & $50 \%$ & Sub condylar & 2 & $12.50 \%$ & Conservative & 1 & $6.25 \%$ \\
\hline Zygomatic & 2 & $12.50 \%$ & & & & Maxilla & 1 & $6.25 \%$ & ORIF & 10 & $62.25 \%$ \\
\hline Upper trunk & 4 & $25 \%$ & & & & ZMC & 11 & $68.75 \%$ & Reduction by gillies & 1 & $6.25 \%$ \\
\hline Main trunk & 2 & $12.50 \%$ & & & & & & & & & \\
\hline
\end{tabular}

ZMC: Zygomatico maxillary complex.

All patients were evaluated postoperatively using the House-Brackmann scale. Comparing the pre and post-operative cut scan and correlating it with the clinical outcome all patients showed satisfactory skeletal reduction. Clinical assessment at 3,6 and 18 months in the outpatient clinic as regard functional and aesthetic outcome of was done. The post-operative average HouseBrackmann score was $2.56( \pm 0.51)$, Table (4) and Diagram (2). Some clinical pre intra and postoperative results are shown in Fig. (1) till (16).

Table (4): Pre and postoperative HB scores with total means.

\begin{tabular}{ccc}
\hline $\begin{array}{c}\text { Patient } \\
\text { No. }\end{array}$ & $\begin{array}{c}\text { Pre-operative } \\
\text { HB score }\end{array}$ & $\begin{array}{c}\text { Post-operative } \\
\text { HB score at } 18 \text { months }\end{array}$ \\
\hline 1 & 5 & 3 \\
2 & 5 & 3 \\
3 & 4 & 2 \\
4 & 5 & 2 \\
5 & 4 & 2 \\
6 & 5 & 3 \\
7 & 5 & 3 \\
8 & 4 & 2 \\
9 & 4 & 3 \\
10 & 5 & 3 \\
11 & 5 & 3 \\
12 & 4 & 2 \\
13 & 5 & 2 \\
14 & 5 & 3 \\
15 & 5 & 2 \\
16 & 5 & 3 \\
\hline Mean & 4.69 & 2.56 \\
SD & 0.48 & 0.51 \\
\hline
\end{tabular}
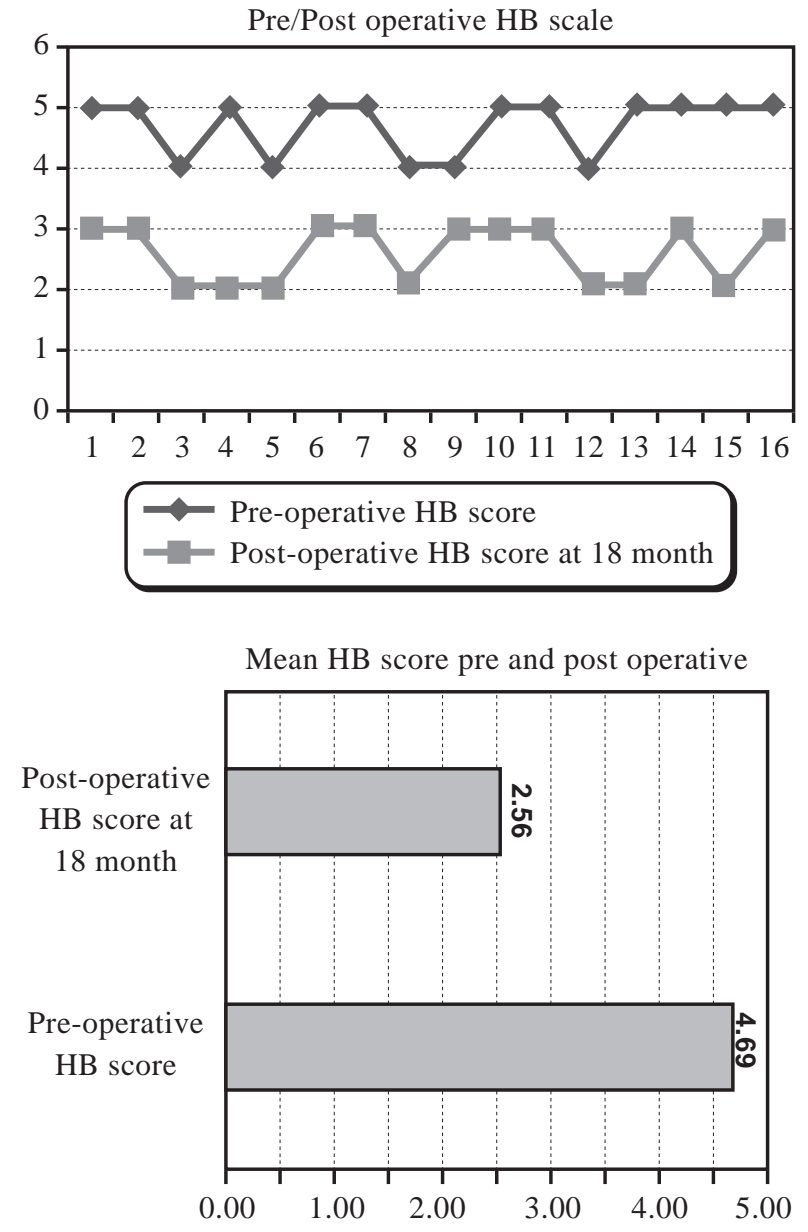

Diagram (2): Pre and postoperative HB score for each patient and mean value. 
Out of the 16 patients, 1 patient $(6.25 \%)$ had hematoma, infection and wound dehiscence which needed 2ry sutures after 3 weeks. Another patient had wound infection which resolved by daily dressing and systemic antibiotics according to the culture and sensitivity. Most common complication was prolonged parotid swelling presented in 5 patients with $31.25 \%$ of all cases Table (5).
Table (5): Complication rate.

\begin{tabular}{lll}
\hline \multicolumn{3}{c}{ Complications } \\
\hline Hematoma & 1 & $6.25 \%$ \\
Infection & 2 & $12.50 \%$ \\
Prolonged parotid gland swelling & 5 & $31.25 \%$ \\
Wound dehiscence & 3 & $18.75 \%$ \\
Hypertrophic scar & 1 & $6.25 \%$ \\
\hline
\end{tabular}
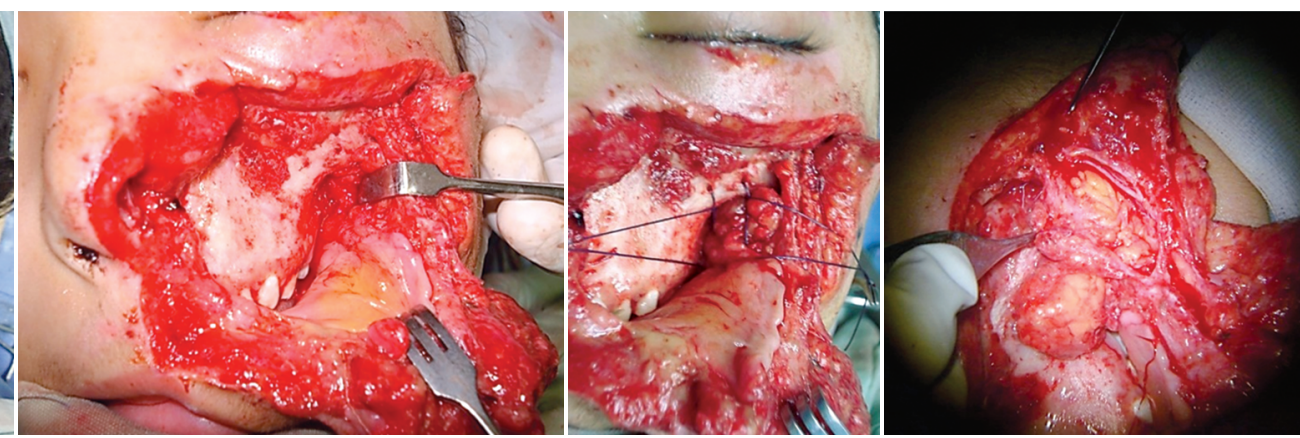

Fig. (1): Pre and intra operative photos of 10 years old female patient, fall from a height, with fracture of upper alveolar bone managed with upper arch bar and injury of the upper trunk of the facial nerve.

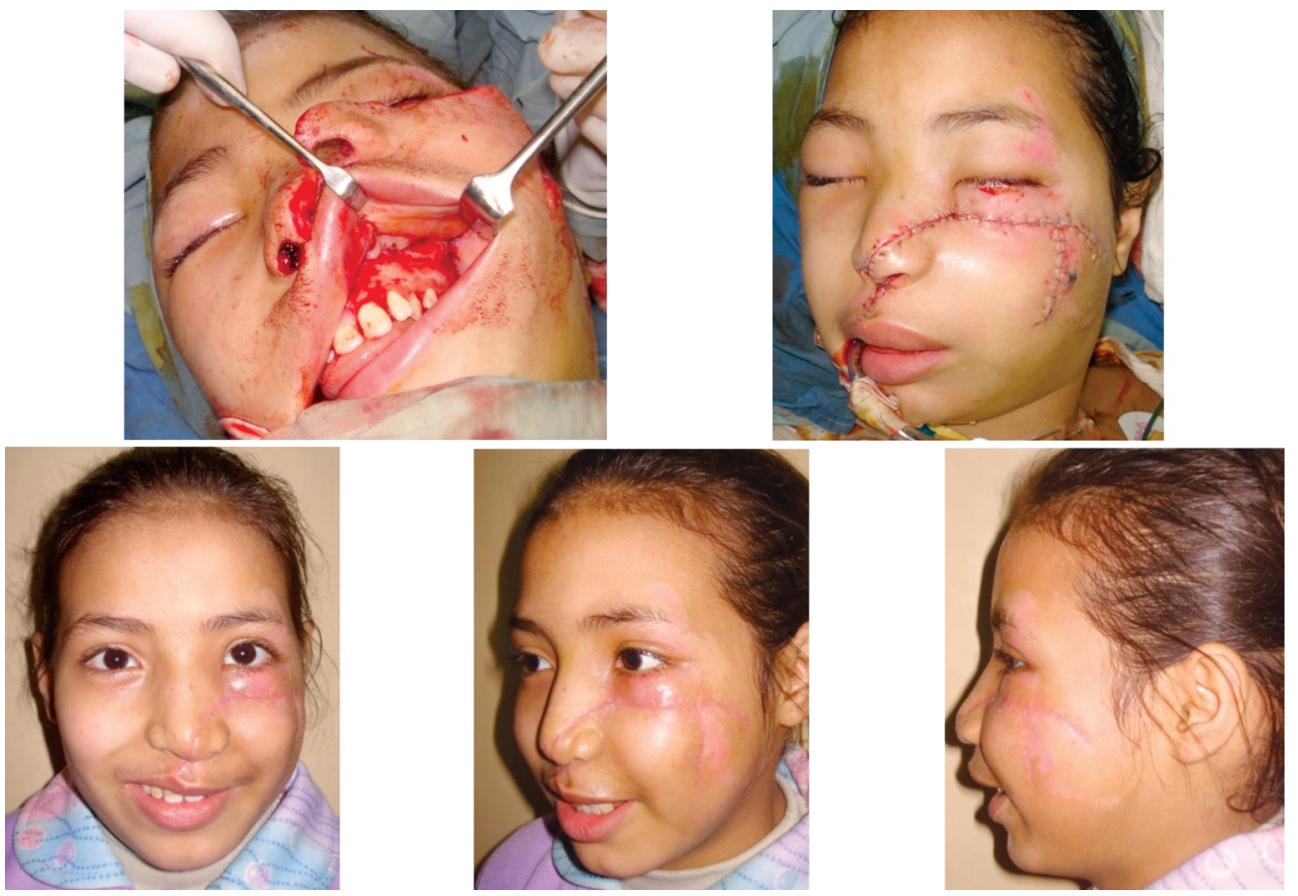

Fig. (2): Immediate and early (3m) post-operative outcome.
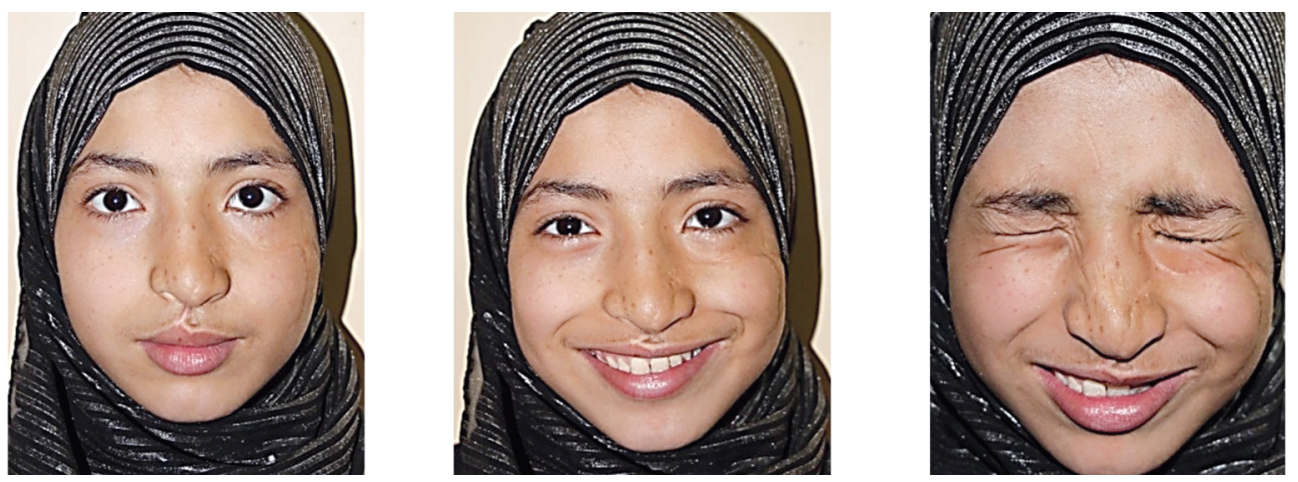

Fig. (3): Late 18 month post-operative outcome. 

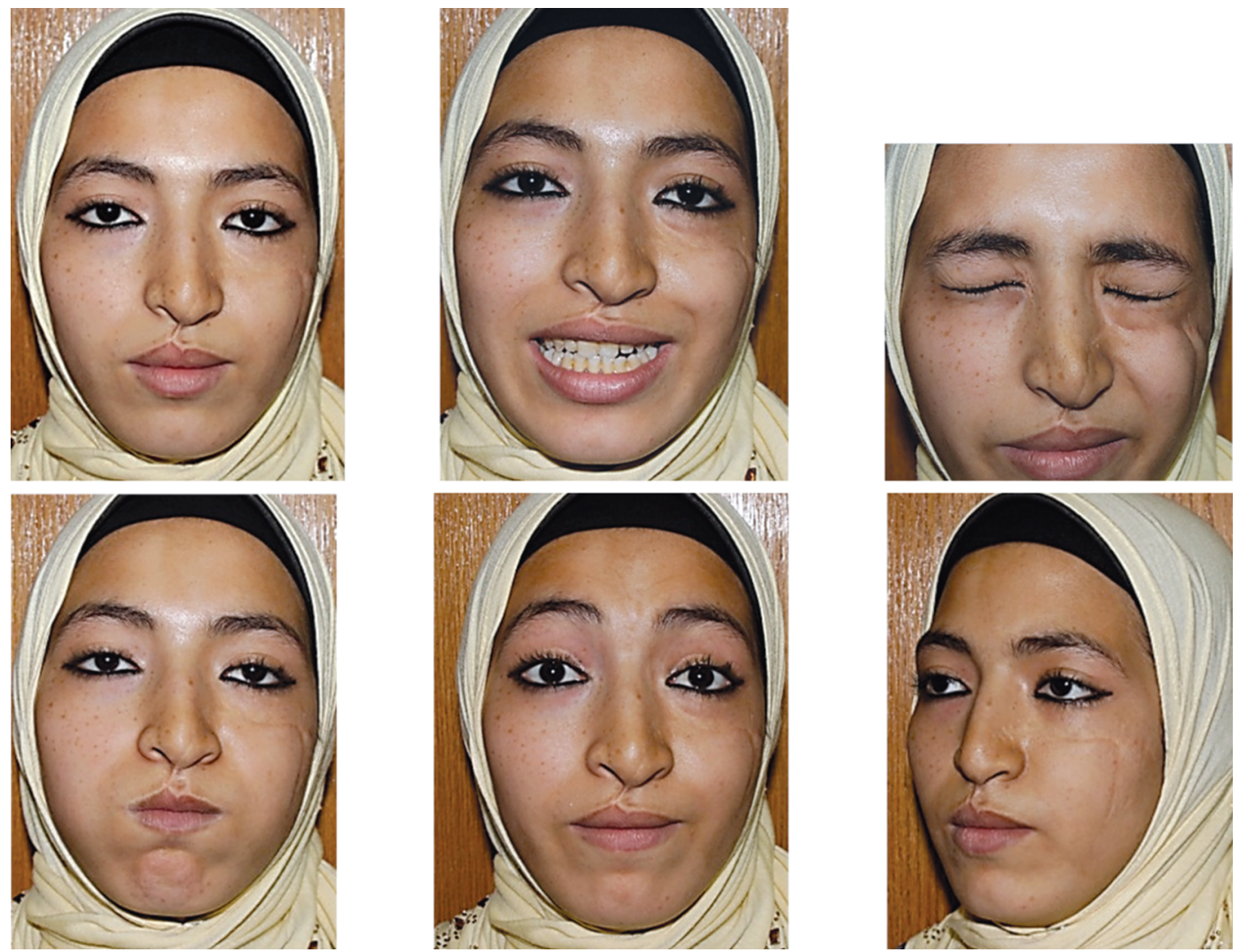

Fig. (4): Late post-operative 28 month outcome.
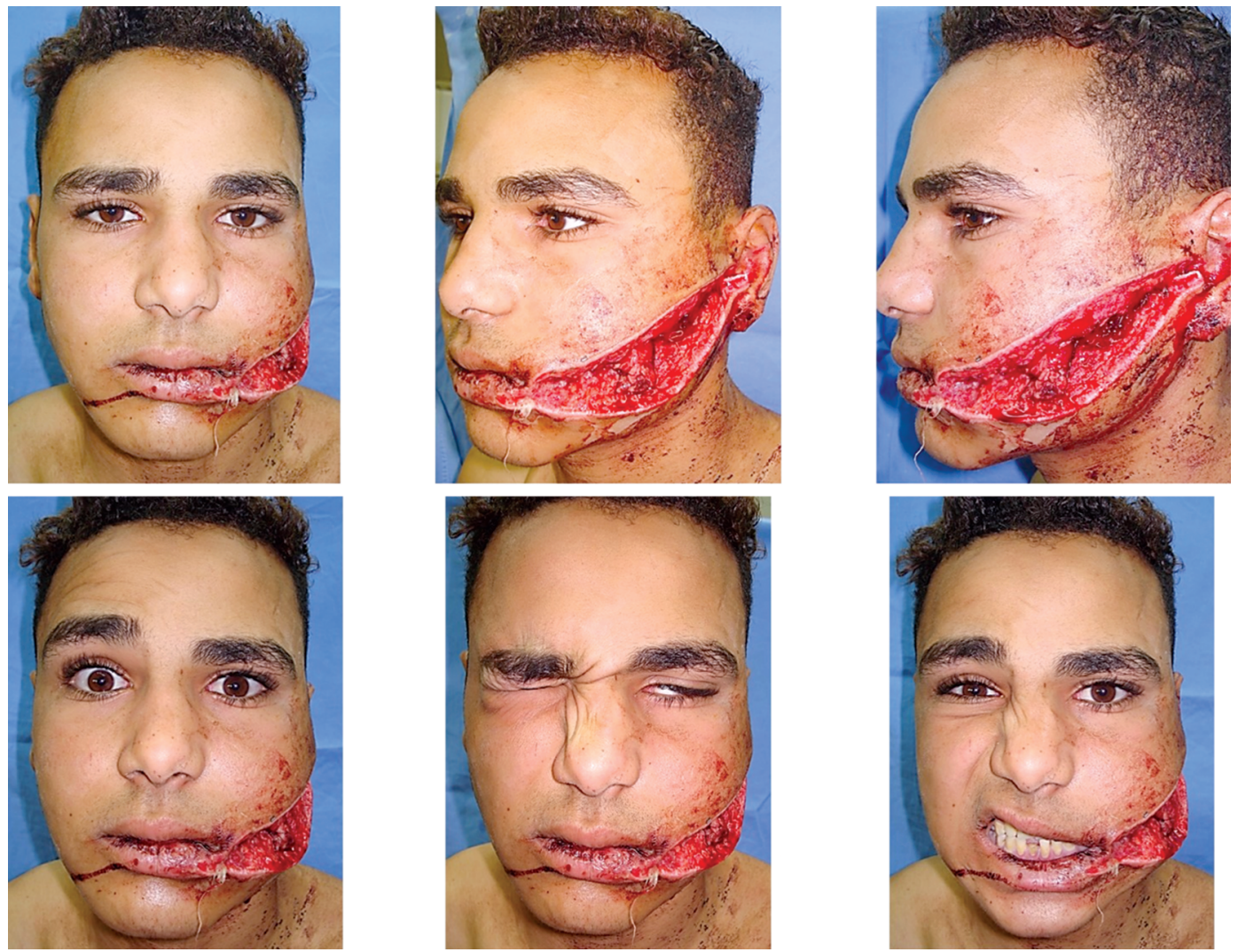

Fig. (5): Pre-operative photos of 16 years old male patient, assaulted with sharp knife, with high sub condylar fracture, parotid duct and gland and upper trunk of facial nerve injury. Managed with upper and lower arch bars, parotid duct, parotid gland, and upper trunk of the facial nerve micro neural repair. 

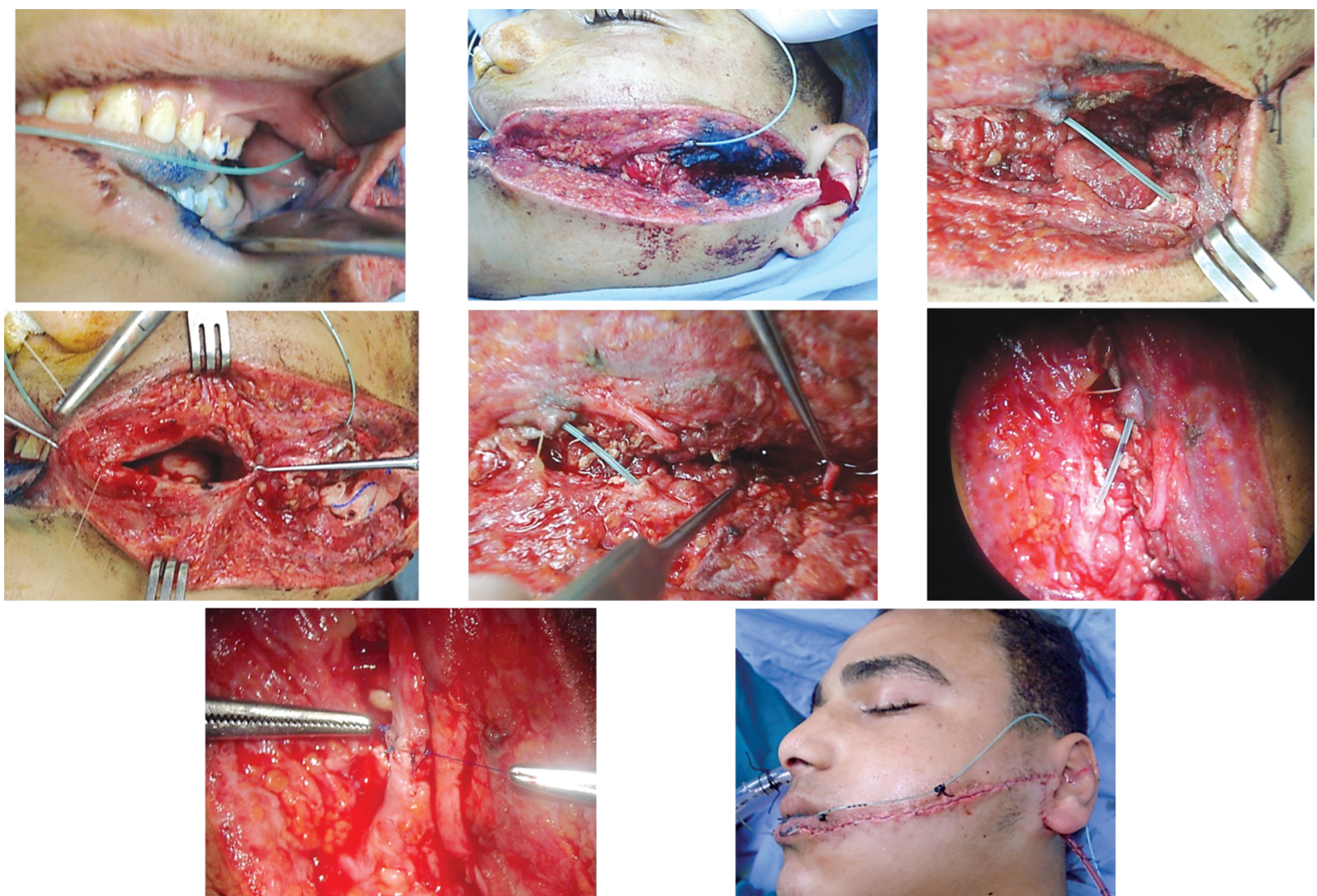

Fig. (6): Intra operative photos identifying the proximal and distal ends of the parotid duct and the proximal and distal ends of the transected upper trunk of the facial nerve and the immediate post-operative outcome.
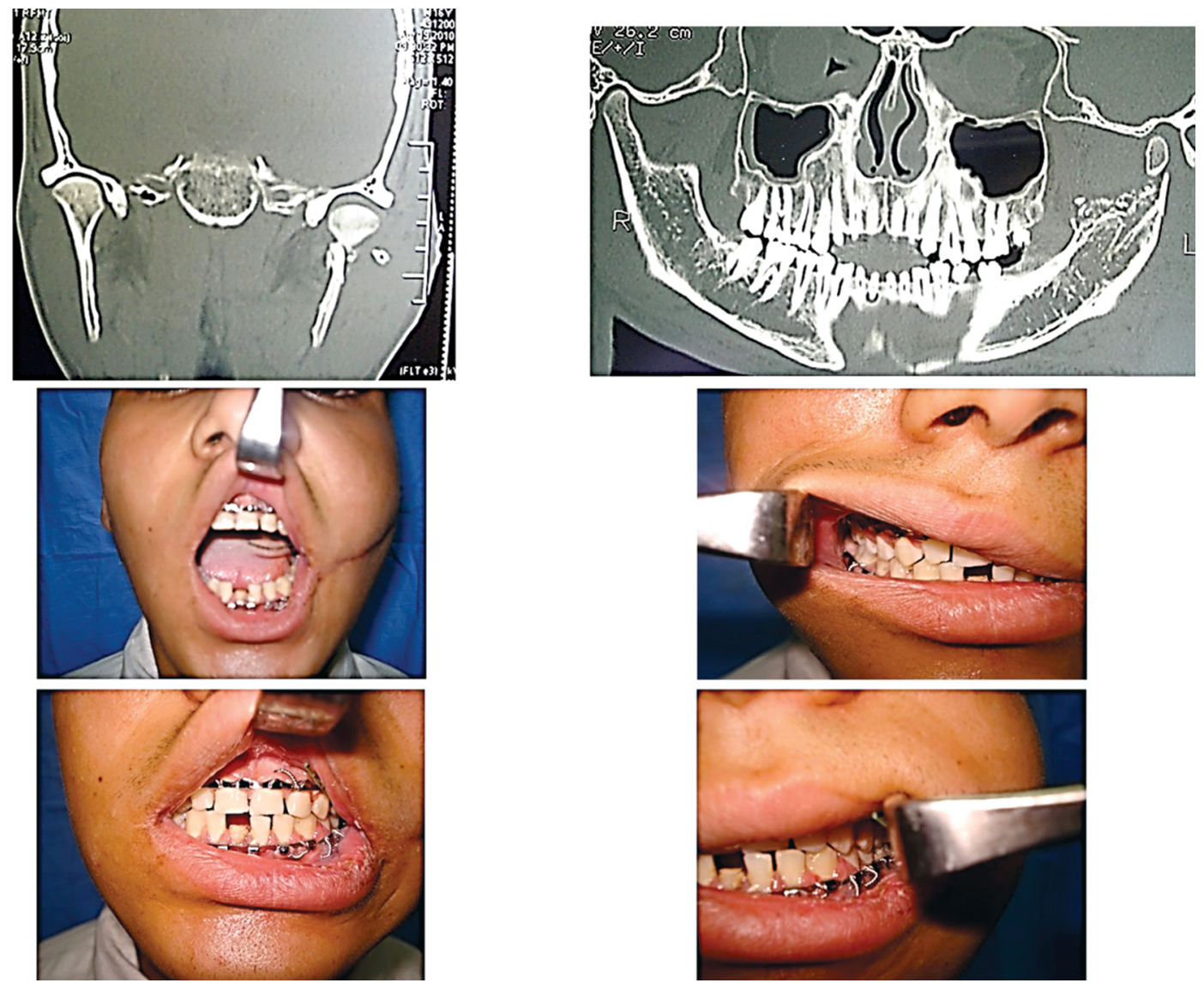

Fig. (7): Preoperative panorama showing the high sub condylar fracture and the post-operative occlusion. 

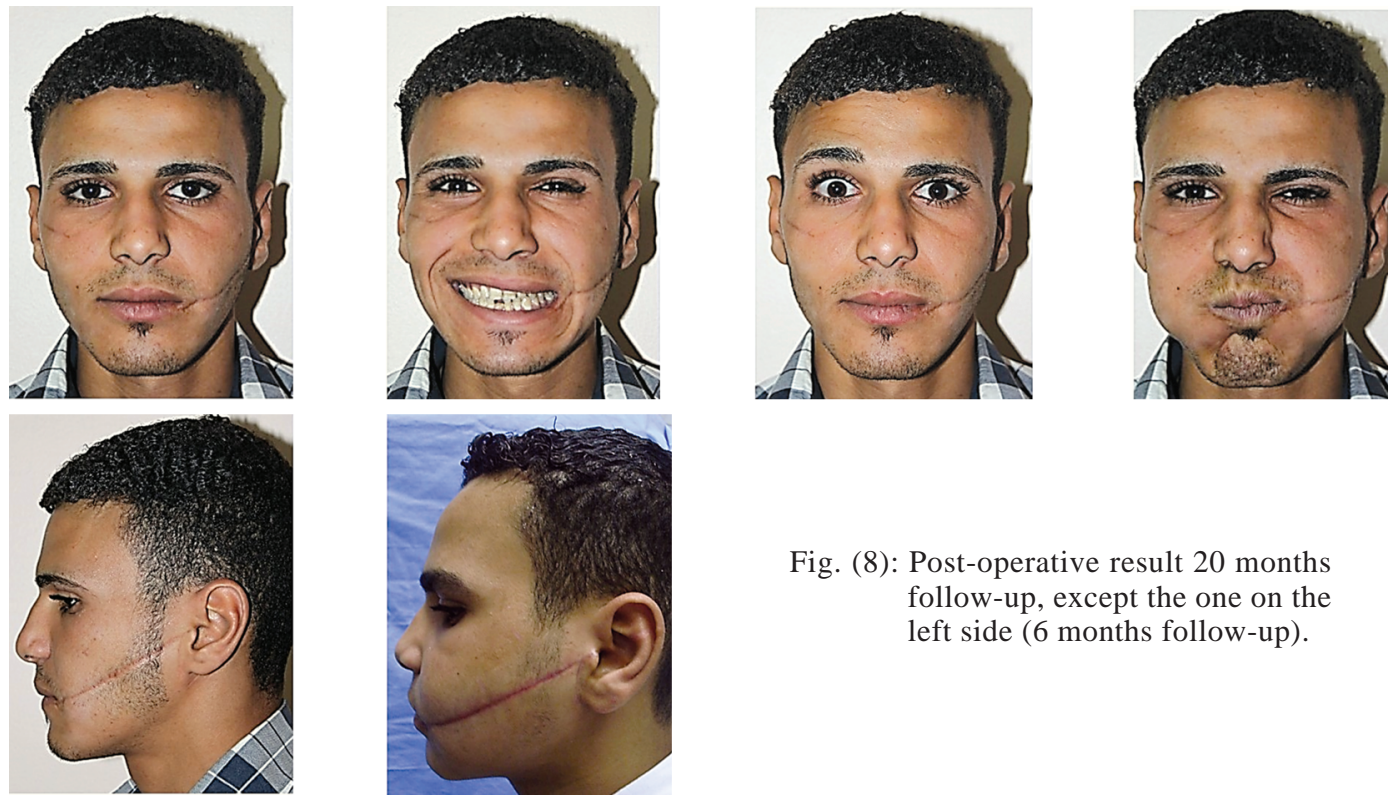

Fig. (8): Post-operative result 20 months follow-up, except the one on the left side (6 months follow-up).
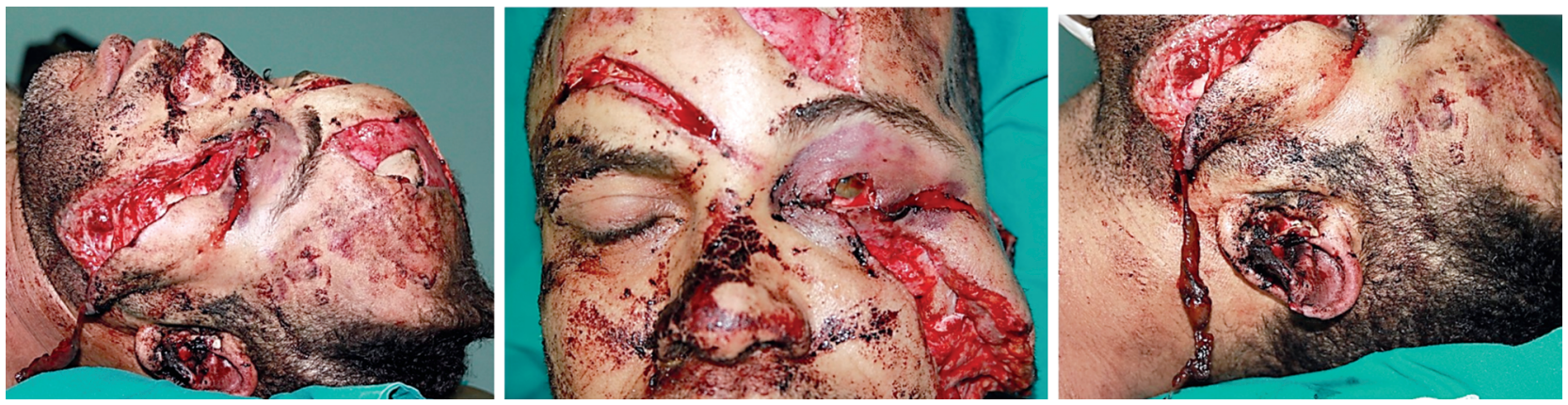

Fig. (9): Pre-operative photos of 43 years old male patient, suffered road traffic accident with buccal branch of facial nerve injury and tetra pod fracture zygoma and floor of the orbit, with associated sever scalp, facial, ear upper and lower eye lid laceration.
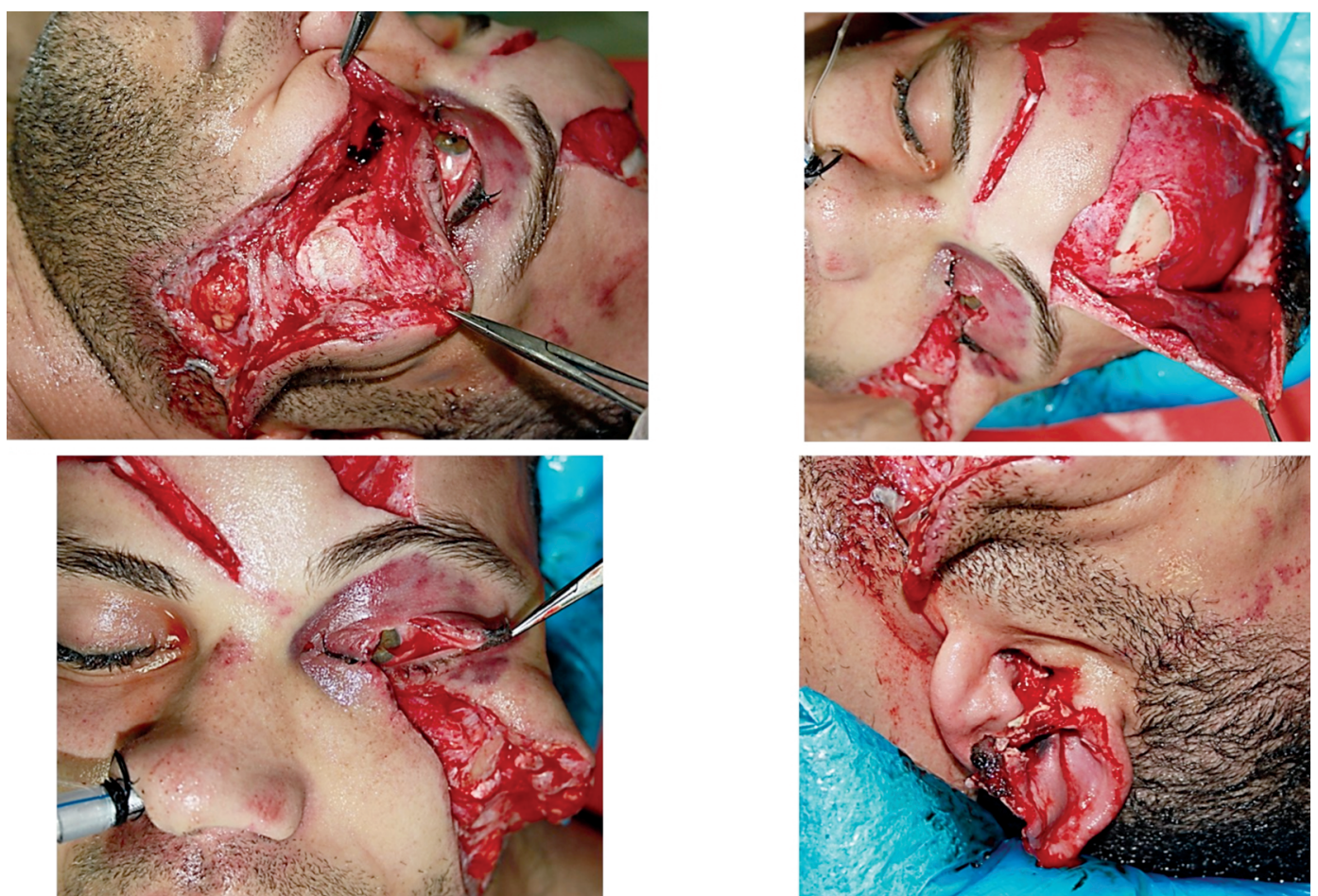

Fig. (10): Intraoperative photos after debridement and identifying structure injured. 

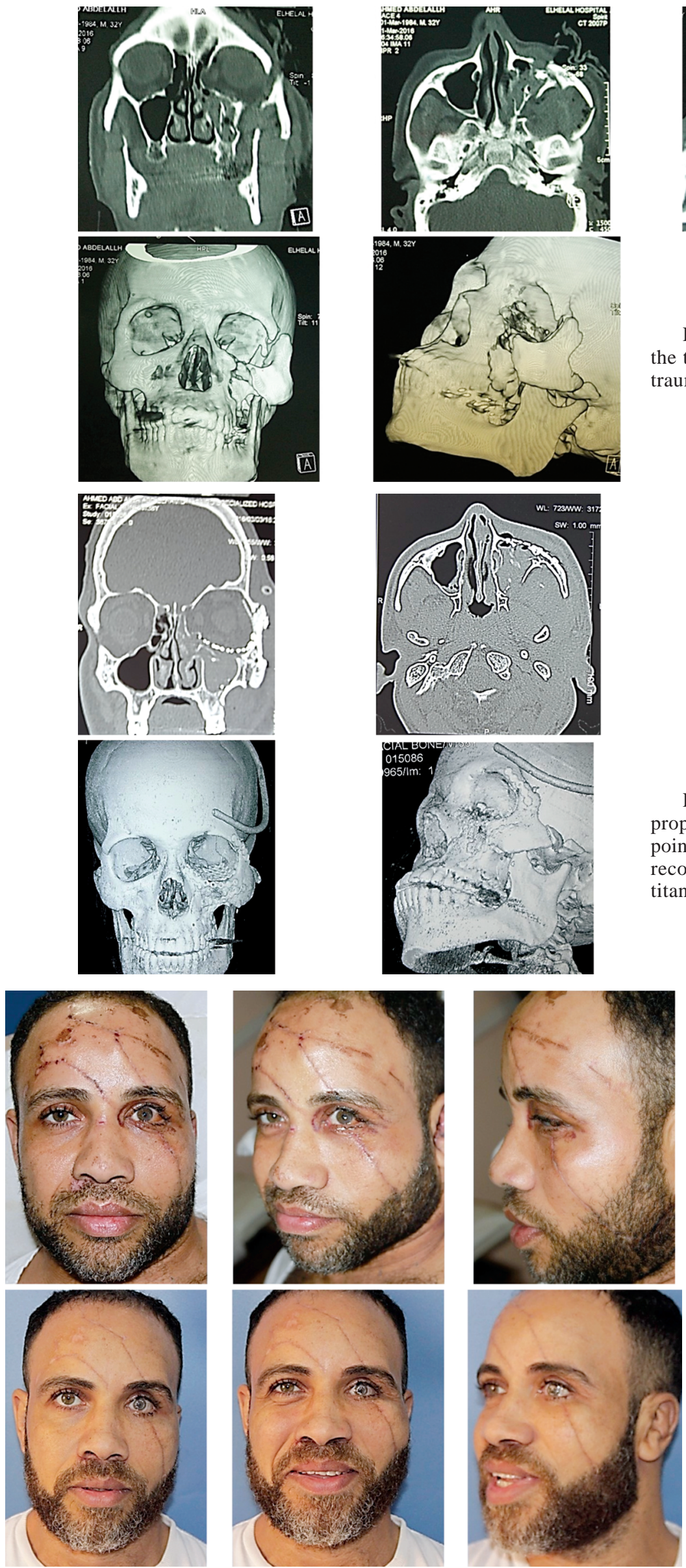

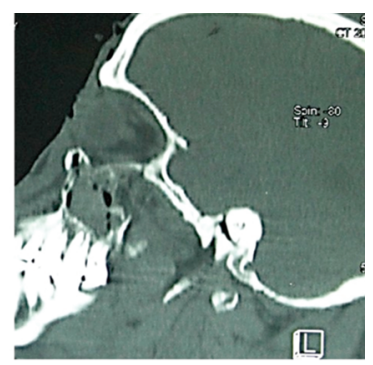

Fig. (11): Pre-operative cut scan showing the tetrapod ZMC fracture and the impact of trauma, displacement and comminusion.

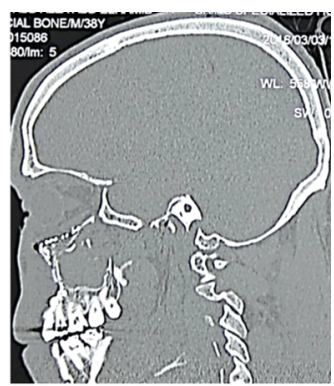

Fig. (12): Post-operative views showing proper alignment of the $\mathrm{ZMC}$ fracture with 3 point fixation with mini plates and screws and reconstruction of the floor of the orbit using titanium mesh.
Fig. (13): Post-operative photos. Upper raw early post-operative outcome (2 month). Lower raw: Late postoperative outcome at 18 months. 

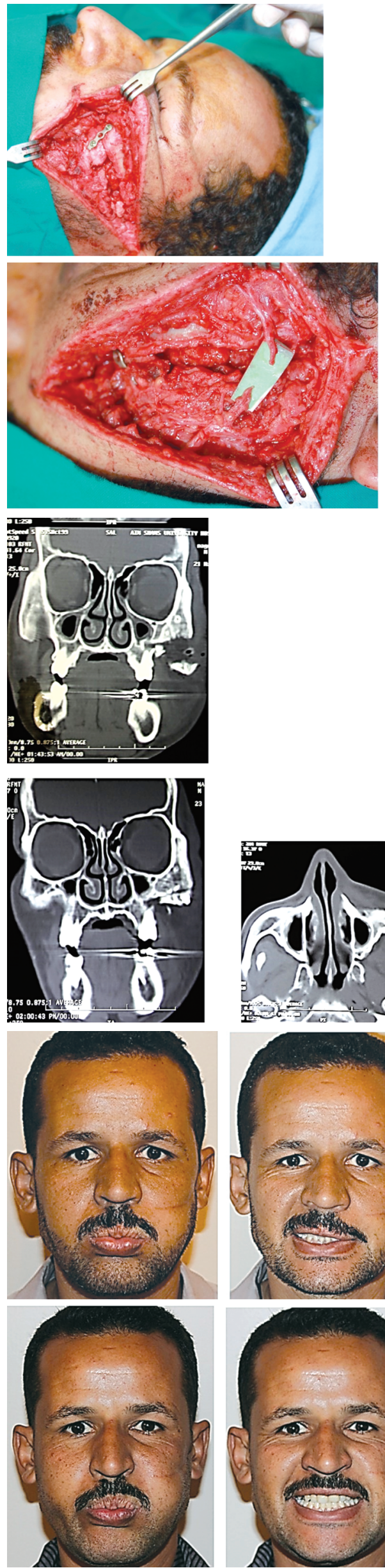
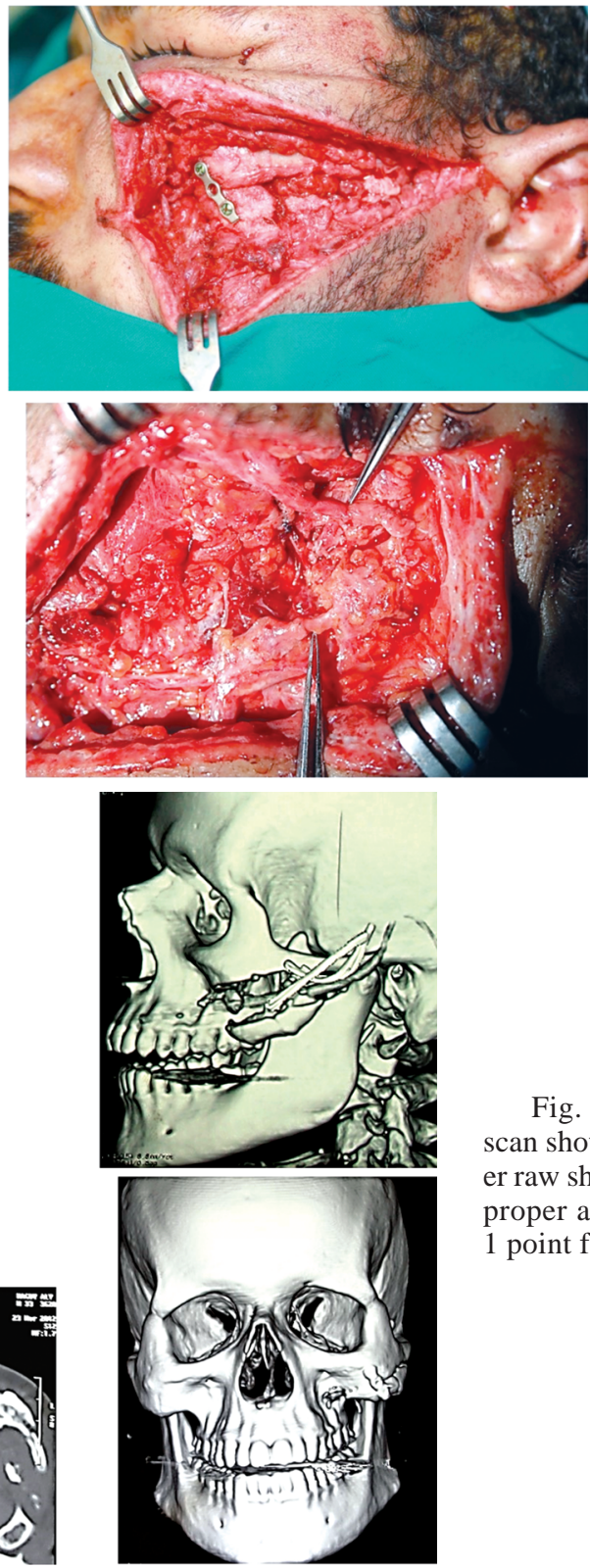
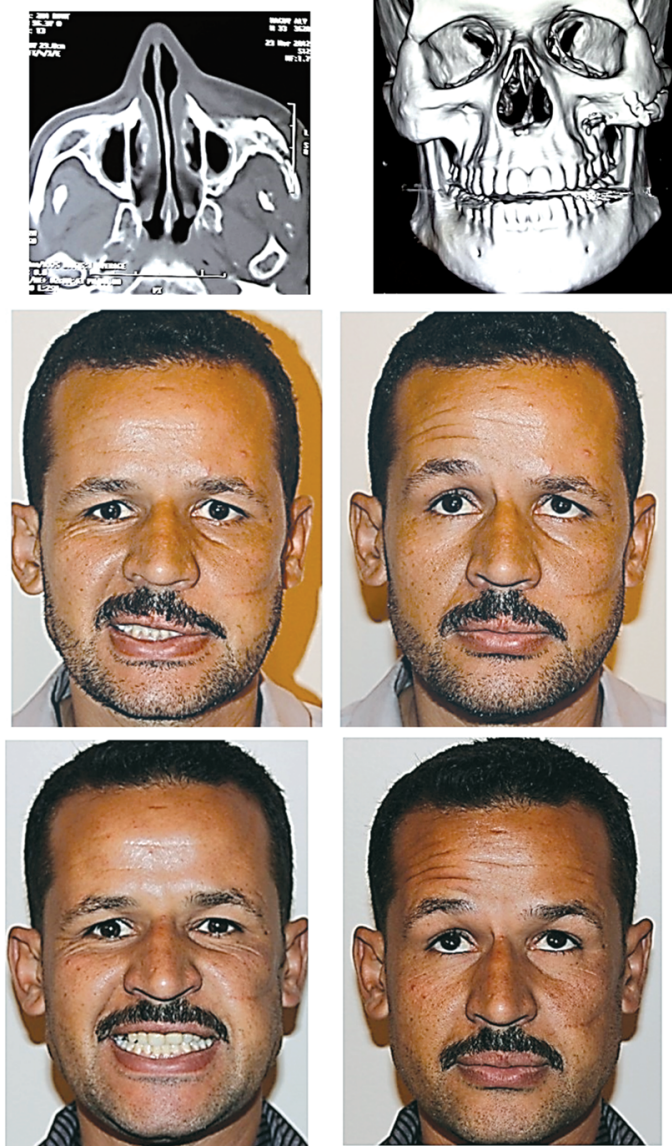

Fig. (15): Upper raw: Pre-operative cut scan showing fracture body of zygoma. Lower raw showing Post-operative views showing proper alignment of the ZMC fracture with 1 point fixation with mini plates and screws.
Fig. (14): Intra operative photos of 36 years old male patient, suffered high velocity impact trauma with main trunk of facial nerve injury, parotid duct, parotid gland and fracture body of zygoma.
Fig. (16): Postoperative photos. Upper raw early post-operative outcome (12 month). Lower raw: Late postoperative outcome at 21 months showing marked improvement. 


\section{DISCUSSION}

Reconstruction of maxillo-facial fractures is considered one of the most challenging procedures for plastic surgeons. It reflects the complexity of the anatomy, the use of varies approaches, strategies, functional, esthetic and psychological impact in trauma patients. In addition to this impact, the facial nerve injuries affect the patients facial expressions, alter the patient self-image, add to the functional deficit and patient's ability to interact and communicate. Facial paralysis affect blink reflex which might threaten vision and affect routine and crucial facial muscle action i.e. Eating and drinking. Therefore, regaining facial nerve function is of utmost importance for better quality of life [12].

After Searching through the English written literature, there is no study investigated the long term outcome of maxillo-facial trauma, fractures and associated with traumatic facial nerve injuries. The present study include patients age ranged from 8 to 51 years old. According to patient's demographics, males $75 \%$ were more common than females. Most common mode of trauma was assaults $44 \%$, high velocity impact $31 \%$, fall from a height $13 \%$ and the least was road traffic accidents $12 \%$. Most common mode of injury in males (assault) was different than female patients (high velocity impact).

In our study treatment plan was tailored according to the site, type and associated structures injured. Facial laceration was adequate for exposure, reduction and fixation of all types of fractures. Temporal region incision was used for reduction of the zygomatic arch in one patient. Subcilliary incision was used in two patients which entailed reconstruction of the orbital floor with titanium mesh. Upper sulcus incision was done in one patient to reduce alveolar fracture, and preauricular incision was carried to explore a high condylar fracture which is managed conservatively afterward.

The zygomatico maxillary complex (ZMC) fractures are the most common type of injuries after nasal bone fractures. It is curtail buttress of the middle one third of the face $[\mathbf{1 3 , 1 4 , 1 5 ]}$. Its articulation with several bones, and its unique tetrapod orientation, signify its effect in the facial prominence, symmetry, width, inferior and lateral orbital regions [16]. Significant complications could be avoided with proper reduction and skeletal fixation, this could be; facial asymmetry, paresthesia, tresmus, epiphora due to obstruction of the nasolacrimal duct, dystopia, diplopia, orbital enopthalmous, and up to blindness $[\mathbf{1 7 , 1 8 , 1 9 ]}$.
Management is debatable, from closed to open reduction and internal fixation, but no standardized strategy exists $[\mathbf{1 4 , 2 0 ]}$. This could be carried using $1,2,3$ or 4 point fixation according to the site, type, degree of comminusion and displacement and stability after reduction $[\mathbf{1 5 , 2 1 , 2 2 ]}$. Gadkari N et al., 2019 did a comprehensive systematic review, aiming to find the best method of fixation with the least incidence of malar asymmetry in the treatment of ZMC fractures. Five articles out of eight showed the superiority of 3 point fixation over the 2 point fixation for these fractures [23].

In our study there was eleven patients with ZMC fractures. All managed with open reduction and internal fixation using mini plate and screws, except one patient with isolated zygomatic arch fracture managed with closed reduction using Gilles approach. Six patients managed with 3 point of fixation, three patients with 2 point fixation and one patient with 1 point of fixation. Four patients had condylar and high condylar fractures managed with application of upper and lower arch bars and elastics, of these one patient had a severely comminuted condylar fracture which is managed conservatively; close follow-up every two days for the $1^{\text {st }}$ week then twice for four weeks, fluid diet for 2 weeks followed by soft diet for another 2 weeks. Lastly one patient had an alveolar fracture managed by applying an upper arch bar.

The more distal the trauma, facial nerve branches are more likely to arborize and the less the repair will be needed. On the contrary, the more proximal the more likely synkinesis to occur after complete recovery. Repair of the facial nerve or its branches should be undertaken at the $1^{\text {st }} 72$ hours of Injury. Lacerations of the facial nerve medial to the lateral canthus is not indicated for repair, as these zygomatic and buccal branches interconnect and are very difficult to identify. Transection of the cervical branch is not indicated for repair unless the patient develops the typical denervation of the platysma muscle and it usually improves within a few weeks [24]. All patients included in the study were operated within the $1^{\text {st }} 48$ hours of trauma. All micro neural repair was done lateral to the lateral canthus of the eye. The most common inured nerves were the buccal branch $37.5 \%$, upper trunk $25 \%$ and temporal zygomatic and main trunk $12.5 \%$ of the patients and this distribution of injuries is related to the type of trauma which is most commonly personal assault.

Realistic goals must be discussed with the patient prior to the surgical intervention which should be discussed as follow; (1) Corneal protec- 
tion; (2) A normal facial musculature resting tone; and (3) A symmetric dynamic smile. Corneal protection is a priority to avoid drastic complications. Patients are always looking for normal or near normal facial appearance without asymmetry at rest. And lastly which is the most challenging dynamic symmetrical smile. Patient satisfaction is possible with proper detailed counseling to explain the goals, outcome, and possible operations for facial reanimation or revision [25]. It is known that nerve repair and anatomical restoration of its integrity provides the best possible results. It must be explained to the patient that the best possible results will be HB grade II-III depending on the site, mode and degree of tissue injury [26]. In our study Clinical assessment at 3,6 and 18 months in the outpatient clinic as regard functional and aesthetic outcome of facial nerve recovery was done. The post-operative average HouseBrackmann score was $2.56( \pm 0.51)$, which is considered acceptable to previous studies and postoperative patient satisfaction.

Previous animal studies investigated the use of the epineurial or perineural type of repair, showing non-significant results between both. The perineural repair is theoretically improves regeneration and decrease synkinesis on the other hand this might lead to trauma and vascular compromise and endoneurial fibrosis $[\mathbf{2 7 , 2 8}]$. Epineurial sheath tube is used with promising results to the epineurial sutures in animal studies [29]. The use of fibrin glue was investigated as well, showing promising outcome $[30,31]$. In the present study epineurial repair was done to all patients using mono filamentous, nonabsorbable type of sutures (ethilon).

Many grading systems have been developed to categorize facial nerve injury. The HouseBrackmann (HB) scale is reliable adopted by the Facial Nerve Disorders Committee of the American Academy of Otolaryngology and Head and Neck Surgery. We used the (HB) scale for the postoperative assisment, as Smith et al., 1992 investigated nine grading systems showing that all grading scales were comparable and HB scale was the simplest and most practical and none was superior over the others. Adding to that the examiner experience was not of significance [32].

Sialocele is a rare complication [33]. There is a possibility of spontaneously regression or nonsurgical treatments could be taken in the form of: Aspiration, compressive dressing, acetylcholine blockers, and botulinum toxin injection $[\mathbf{3 4 , 3 5 ]}$. In our study most common complication was prolonged parotid swelling presented in 5 patients with $31.25 \%$ of all cases. One patient 42 years old, diabetic hypertensive ad smoker had hematoma, wound infection and dehiscence which required evacuation and 2ry suture.

\section{Conclusion:}

This study revealed that the long term result for patients with combined repair of traumatic facial nerve and varies maxillofacial fractures had promising esthetic and functional outcome which was not investigated in previous English written studies. It was proven by the post-operative objective assessment using House-Brackmann score analysis that the average result was very satisfactory comparable with previous studies of facial nerve recovery.

As the combination of traumatic facial nerve inurey and maxillo-facila fractures is not common as isolated $\mathrm{ZMC}$ fractures, further multi-centric study is suggested to investigate the relation between the type of trauma, different nerves involved, and surgical outcome. Also Botox injection in the parotid gland to be added in the post-operative armamentarium as it is common to have prolonged post-operative swelling due to traumatic parotid fascia injury.

\section{Acknowledgments:}

I would like to thank all the residents, nursing staff and outpatient clinic personnel of the plastic and maxillofacial surgery and physical medicine and rehabilitation department for their endless support and the postoperative care of the patients included in the study.

\section{REFERENCES}

1- Rowe N.L. and Williams J.L.: Fractures of the zygomatic complex and orbit. In: Williams J.L. (ed) 'Rowe and Williams' maxillofacial injuries, Vol. I, $2^{\text {nd }}$ edn, Churchill Livingstone, Edinburgh, pp. 475-590, 1994.

2- Vrinceanu D. and Banica B.: Principles of surgical treatment in the midface trauma-theory and practice. Maedica (Buchar), 9 (04): 361-366, 2014.

3- Kaur J. and Chopra R.: Three dimensional CT reconstruction for the evaluation and surgical planning of mid face fractures: A 100 case study. J. Maxillofac. Oral Surg., 9 (04): 323-328, 2010.

4- Odebode T.O. and Ologe F.E.: Facial nerve palsy after head injury: Case incidence, causes, clinical profile and outcome. J. Trauma, 61: 388-91, 2006.

5- Yetiser S., Hidir Y. and Gonul E.: Facial nerve problems and hearing loss in patients with temporal bone fractures: demographic data. J. Trauma, 65: 1314-20, 2008.

6- Melvin T.A. and Limb C.J.: Overview of facial paralysis: Current concepts. Facial Plast. Surg., 24: 155-163, 2008. 
7- Schaitkin B. and May M.: Disorders of facial nerve inurey: Kerr A.G., Booth J.B., editors. Scott Brown's otolaryngology. $6^{\text {th }}$ ed. Oxford: Butterworth - Heinemann, p.124, 1997.

8- Miloro M., Ghali G.E., Larsen P.E., et al.: Peterson's principles of oral and maxillofacial surgery. $2^{\text {nd }}$ ed. Hamilton: BC Decker Inc., p. 358, 2004.

9- Grosheva M., Wittekindt C. and Guntinas-Lichius O.: Prognostic value of electro neurography and electromyography in facial palsy. Laryngoscope, 118: 394-7, 2008.

10- Aviv J.E. and Urken M.L.: Management of the paralyzed face with micro neu-Rovascular free muscle transfer. Arch. Otolaryngol. Head Neck Surg., 118: 909-12, 1992.

11- House J.W. and Brackmann D.E.: Facial nerve grading system. Otolaryngol. Head Neck Surg., 93: 146-147, 1985.

12- Faris C. and Lindsay R.: Current thoughts and developments in facial nerve reanimation. Curr. Opin. Otolaryngol. Head Neck Surg., 21: 346-352, 2013.

13- Ellis E. 3 ${ }^{\text {rd }}$, El-Attar A. and Moos K.F.: An analysis of 2,067 cases of zygomatico-orbital fracture. J. Oral Maxillofac. Surg., 43: 417-28, 1985.

14- Zingg M., Laedrach K., Chen J., et al.: Classification and treatment of zygomatic fractures: A review of 1,025 cases. J. Oral Maxillofac. Surg., 50: 778-90, 1992.

15- Marinho R.O. and Freire-Maia B.: Management of fractures of the zygomaticomaxillary complex. Oral Maxillofac. Surg. Clin. North Am., 25: 617-36, 2013.

16- Brennan P., Schliephake H., Ghali G. and Cascarini L.: Max Surg. $3^{\text {rd }}$ ed. St. Louis, MO: Elsevier, 93-94, 2017.

17- Kovacs A.F. and Ghahremani M.: Minimization of zygomatic complex fracture treatment. Int. J. Oral Maxillofac. Surg., 30: 380Y383, 2001.

18- Vriens J.P., van der Glas H.W., Moos K.F., et al.: Infraorbital nerve function following treatment of orbitozygomatic complex fractures. A multitest approach. Int. J. Oral Maxillofac. Surg., 27-32, 1998.

19- Enislidis G., Pichorner S., Kainberger F., et al.: Lactosorb panel and screws for repair of large orbital floor defects. J. Craniomaxillofac. Surg., 25: 316-321, 1997.

20- Lee E.I., Mohan K., Koshy J.C., et al.: Optimizing the surgical management of zygomaticomaxillary complex fractures. Semin Plast. Surg., 24: 389-97, 2010.

21- Brennan P., Schliephake H., Ghali G. and Cascarini L.: Max Surg $3^{\text {rd }}$ ed. St. Louis, MO: Elsevier, 93-94, 2017.
22- Meslemani D. and Kellman R.M.: Zygomaticomaxillary complex fractures. Arch. Facial Plast. Surg., 14: 62-66, 2012.

23- Gadkari N., Bawane S., Chopra R., Bhate K., Kulkarni D.: Comparative evaluation of 2-point vs 3-point fixation in the treatment of zygomaticomaxillary complex fractures - A systematic review. J. Craniomaxillofac. Surg., 47 (10): 1542-1550, 2019.

24- Ellenbogen R.: Pseudo-paralysis of the mandibular branc of the facial nerve after platysmal face-lift operation. Plast. Reconstr. Surg., 63: 364, 1979.

25- Wells M.D. and Manktelow R.T.: Surgical management of facial palsy. Clin. Plast. Surg., 17 (4): 645, 1990.

26- Millesi H.: Nerve suture and grafting to restore the extratemporal facial nerve. Clin. Plast. Surg., 6: 333, 1979.

27- Gross M., Sichel J.Y. and Eliashar R.: Cable graft repair of iatrogenic facial nerve injury. Injury Extra, 35: 59-60, 2004.

28- Guntinas-Lichius O., Streppel M. and Stennert E.: Postoperative functional evaluation of different reanimation techniques for facial nerve repair. Am. J. Surg., 191: 617, 2006 .

29- Yavuzer R, Ayhan S., Latifoğlu O., et al.: Turnover epineurial sheath tube in primary repair of peripheral nerves. Ann. Plast. Surg., 48: 392-400, 2002.

30- Shipchandler T.Z., Seth R. and Alam D.S.: Split hypoglossal-facial nerve neurorraphy for treatment of the paralyzed face. Am. J. Otolaryngol., 32: 5116, 2011.

31- Biglioli F., Frigerio A. and Colombo V.: Masseteric-facial nerve anastomosis for early facia lreanimation. J. Craniomaxillofac. Surg., 40: 149-55, 2012.

32- Smith I.M., Murray J.A., Cull R.E., et al.: A comparison of facial Grading systems. Clin. Otolaryngol. Allied Sci., 17: 303-307, 1992.

33- Richards A.T., Digges N., Norton N.S., Quinn T.H., Say P. and Galer C.: Surgical anatomy of the parotid duct with emphasis on the major tributaries forming the duct and the relationship of the facial nerve to the duct. Clin. Anat., 17: 463-7, 2004.

34- Araujo M.R., Centurion B.S., Albuquerque D.F., Marchesano L.H. and Damante J.H.: Management of a parotid sialocele in a young patient: Case report and literature review. J. Appl Oral Sci., 18: 432-6, 2010.

35- Parekh D., Glezerson G., Stewart M., Esser J. and Lawson H.H.: Post-traumatic parotid fistulae and sialoceles: A prospective study of conservative management in 51 cases. Ann. Surg., 209: 105-11, 1989. 